\title{
Effect of Biomass Source on the Physico-mechanical Properties of Polyurethane Foam Produced by Microwave-assisted Liquefaction
}

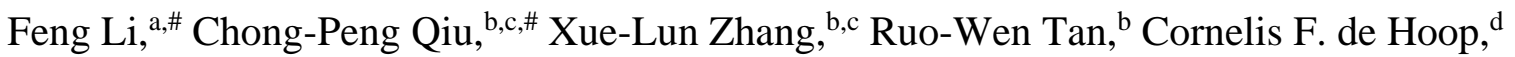
Jay P. Curole, ${ }^{\mathrm{d}}$ Jin-Qiu Qi, ${ }^{\mathrm{b}}$ Hui Xiao, ${ }^{\mathrm{b}}$ Yu-Zhu Chen, ${ }^{\mathrm{b}}$ Jiu-Long Xie, ${ }^{\mathrm{b}}$ Yong-Ze Jiang, ${ }^{\mathrm{b}}$ Shao-Bo Zhang, ${ }^{\mathrm{b}}$ Wen-Jing Guo, ${ }^{\mathrm{e}}$ and Xing-Yan Huang ${ }^{\mathrm{b}, \mathrm{c}, *}$

\begin{abstract}
Different biomass sources (bamboo, rape straw, lignin, and Yaupon holly) were liquefied using microwave energy to produce biopolyols, which were then used to prepare biofoams without any further separation process. The results indicated that the content of hydroxyl groups in biopolyols derived from different biomass sources was sorted in descending order as rape straw, Yaupon holly, bamboo, and lignin. The rheological analysis demonstrated that the biopolyols were pseudoplastic, and the yield stress of biopolyols was remarkably increased with increasing biomass content. The compressive strength of polyurethane (PU) foam was rendered smaller by introducing biomass sources. Nevertheless, the biofoam obtained from biomass sources with higher hydroxyl groups content had better PU performance. In addition, the termite resistance performance of PU foam increased with the introduction of Yaupon holly, rape straw, and bamboo sources. Accordingly, the biofoams derived from the liquefaction of rape straw performed better than those from other biomass sources.
\end{abstract}

Keywords: Liquefaction; Polyurethane foam; Rheological analysis; Termite resistance

Contact information: a: Landscape Architecture School, Chengdu Agricultural College, Chengdu, Sichuan 611130, PRChina; b: College of Forestry, Sichuan Agricultural University, Chengdu, Sichuan 611130, PRChina; c: Wood Industry and Furniture Engineering Key Laboratory of Sichuan Provincial Department of Education, Chengdu, Sichuan 611130, PRChina; d: School of Renewable Natural Resources, Louisiana State University Agricultural Center, Baton Rouge, LA 70803, USA; e: Research Institute of New Forest Technology, Chinese Academy of Forestry, Beijing 100091, PRChina; \#: Feng Li and Chong-Peng Qiu are co-first authors; *Corresponding author: hxy@sicau.edu.cn

\section{INTRODUCTION}

Polyurethane (PU) foam is one of the most versatile petroleum-based materials due to its low density, low thermal conductivity, and high mechanical performance (Zhang and Kessler 2015). It has been widely used in construction, packaging, and furniture production (Kausar 2017). With growing concerns for environmental damage and the rapid depletion of fossil fuels, massive efforts have focused on substituting petroleum-based polyols with bio-based ones, such as the biopolyol derived from biomass liquefaction (Huang et al. 2017a, 2018a).

Liquefaction is a promising way to convert biomass into valuable chemicals (Huang et al. 2017a). The main chemical components-namely, cellulose, hemicellulose, and lignin - in biomass can be broken down to lower molecular chemicals with numerous hydroxyl groups, such as C5 sugars, C6 sugars, and aromatics during the liquefaction process (Huang et al. 2017a). It has been demonstrated in previous works that the biopolyol produced by liquefaction is a promising feedstock with which to prepare bio-based PU 
foam (Huang et al. 2017b, 2018b). Moreover, a considerable amount of biomass has been liquefied to prepare bio-based PU foams in different works, such as cornstalks (Yan et al. 2008), sugar cane bagasse (Hakim et al. 2011), wheat straw (Chen and Lu 2009), wood (Huang et al. 2018a), rape straw (Huang et al. 2018b), and lignin (Xue et al. 2015). Unfortunately, there are no comparisons among these works because the liquefaction parameters, including solid-liquid ratio, reaction conditions, catalyst, are different, resulting in a variability in the physico-mechanical properties of biopolyols (Huang et al. 2017b; da Silva et al. 2017). In addition, different amounts of bio-polyol substitution in the foaming process can cause the changes in bio-based foam properties.

Therefore, the liquefaction parameters were fixed to comparatively analyze the effect of selected biomass sources - specifically, bamboo, rape straw, lignin, and Yaupon holly - on the physico-mechanical properties of bio-based PU foams. The effect of the amounts of biopolyol substitution was investigated in this work as well. In particular, the microwave-assisted liquefaction products without any separation were used directly to produce bio-based PU foams. The characteristics of biopolyol were analyzed by Fourier transform infrared spectroscopy (FTIR) and a rheometer. The physico-mechanical properties, including the thermal stability, compressive strength, and termite resistance of the resulting biofoams, were evaluated in this work.

\section{EXPERIMENTAL}

\section{Materials}

Bamboo and rape straw were collected from the Sichuan province in China, and Yaupon holly was harvested at the Bob R. Idlewid Research Station near Clinton, LA, USA. Lignin was purchased from VWR International (Radnor, PA, USA). These raw materials were ground into 60- to 80-mesh particles using a Thomas Wiley Laboratory mill (Swedesboro, NJ, USA), and then oven-dried at $105^{\circ} \mathrm{C}$ until constant weight.

Dibutyltin dilaurate (Pfaltz \& Bauer, Waterbury, CT, USA) and 98\% sulfuric acid $\left(\mathrm{H}_{2} \mathrm{SO}_{4}\right)$ and was purchased from VWR International (Radnor, PA, USA). Materials kindly supplied by Huntsman Polyurethanes (Woodlands, TX, USA) were: polymeric methylene diphenyl diisocyanate (pMDI) (brand name: Rubinate $\mathrm{M}$ ) with an average functionality of 2.7; isocyanate groups (NCO), content of $31.0 \%$ and viscosity of $192 \mathrm{cps}$ at $25{ }^{\circ} \mathrm{C}$; glycerol-based polyol with a hydroxyl value of $238 \mathrm{mg} \mathrm{KOH} / \mathrm{g}$ (brand name: Jeffol FX 31240); and a catalyst, dimethylcyclohexylamine (brand name: Jeffcat DMCHA) (Huntsman Corporation, Woodlands, TX, USA).

Dow Corning 193 (a silicone polyether surfactant from Dow Corning Corporation, Midland, MI, USA) and deionized water were used as surfactant and blowing agent, respectively. All chemicals were used without further purification.

\section{Methods}

Preparation of biopolyol

Liquefaction of bamboo, lignin, rape straw, and Yaupon holly were performed in a Milestone laboratory microwave oven (ETHOS EX, Shelton, CT, USA) equipped with an ATC-400FO automatic fiber optic temperature control system. A typical run for different biomass sources liquefaction ( $20 \%$ biopolyol substitution) was carried out with a loading of $2.4 \mathrm{~g}$ raw material, $12 \mathrm{~g}$ polyol, and $0.24 \mathrm{~g}$ sulfuric acid at $140{ }^{\circ} \mathrm{C}$ for $10 \mathrm{~min}$ (increasing 
temperature for $5 \mathrm{~min}$ and maintained for $5 \mathrm{~min}$ ). After liquefaction, the black products were used directly to produce bio-based PU foams.

\section{Preparation of biofoams}

The PU foams were prepared using a one-step method. A mixture of $3.00 \mathrm{~g}$ liquefaction mixtures, including polyol productions and unliquefied powders, $0.30 \mathrm{~g}$ cocatalyst (Jeffcat DMCHA: dibutyltindilaurate = 1:1), $0.20 \mathrm{~g}$ deionized water, and $0.20 \mathrm{~g}$ surfactant was thoroughly premixed with a mechanical stirrer for $1 \mathrm{~min}$, followed by the addition of $10 \mathrm{~g}$ pMDI via stirring at $1500 \mathrm{rpm}$. The foams were allowed to freely rise in open plastic cylindrical cups and to cure overnight before testing. The PU foams with $0 \%$, $10 \%, 20 \%$, and $30 \%$ (by pure polyol) of Yaupon holly were labeled as PU0, PU10, PU20 (also named as PUY), and PU30, respectively. The foams containing 20\% (by pure polyol) of different biomass sources (rape straw, bamboo, and lignin) were named as PUR, PUB, and PUL, respectively.

\section{Chemical analysis of biopolyol}

The FTIR spectrum of biopolyol was performed on a Nicolet Nexus670 spectrometer (Madison Instruments, Middleton, WI, USA) equipped with a Thermo Nicolet Golden Gate MKII Single Reflection ATR accessory. A small amount of sample was covered flatwise on the detection window. The scanning range of wavenumbers was from 4000 to $400 \mathrm{~cm}^{-1}$ with a resolution of $4 \mathrm{~cm}^{-1}$. A total of 32 scans were collected.

\section{Rheological properties of biopolyol}

The rheological properties of biopolyol were measured using a stress-controlled rheometer of AR 2000 (AR-G2; TA Instruments, New Castle, DE, USA) equipped with a DIN concentric cylinder geometry. It consisted of a rotator with a diameter of $28.03 \mathrm{~mm}$ and a stainless-steel cup with a diameter of $30.38 \mathrm{~mm}$. The rheological curves were obtained by measuring the viscosity or shear stress as a function of shear rate in the range of 0.1 to $1000 \mathrm{~s}^{-1}$ at $25^{\circ} \mathrm{C}$.

The rheological data of biopolyol were fitted to two different rheological models using Origin software (Originlab Corporation, v.2018C, Northampton, MA, USA). One of the most popular and efficient models to fit the relation between shear stress and shear rate is the Herschel-Bulkley model (Herschel and Bulkley 1926), which has the following form,

$$
\tau=\tau_{0}+K \dot{\gamma}^{n}
$$

where $\tau$ is the shear stress $(\mathrm{Pa}), \tau_{0}$ is the yield stress $(\mathrm{Pa}), K$ is the flow consistency coefficient, $\dot{\gamma}$ is the shear rate $\left(\mathrm{s}^{-1}\right)$, and $n$ is the flow behavior index. This model has been successfully used to describe the rheological properties of biopolyol obtained from the liquefaction of cellulose (Kosmela et al. 2016). Because this model cannot give a unique fit for a given data set, the rheological properties of biopolyol were also analyzed using an improved model, namely, the Sisko model (Sisko 1958), as given below,

$$
\tau=\mu_{\infty} \dot{\gamma}+K \dot{\gamma}^{n}
$$

where $\mu_{\infty}$ is the viscosity at infinite shear rate $\left(\mathrm{s}^{-1}\right), K$ is the flow consistency coefficient, and $n$ is the flow behavior index. This model performed well in describing the rheological properties of complex fluids over the entire range of shear rate, for example, in drilling fluids (Li et al. 2016). 


\section{Mechanical properties of biofoams}

An eXpert2610 universal mechanical test analyzer (ADMET, Norwood, MA, USA) was used to measure the compressive strength of the foams, according to the ASTM D69510 (2010). Samples were placed between the two parallel plates and compressed at 10 $\mathrm{mm} / \mathrm{min}$. The Young's modulus was calculated by the slope of the tangent of linear portion in the stress-strain profile in accordance with the method described in previous reports (Gama et al. 2015). The compressive strength was taken from the stress-strain curves at a deformation of $20 \%$. Ten replicates were measured for each group.

\section{Chemical analysis of biofoams}

The chemical analyses of PU foams were also characterized using FTIR.

Thermogravimetric analysis (TGA) of biofoams

Thermogravimetric analysis (TGA) with a thermal analyzer (Q50 TGA; TA Instruments, New Castle, DE, USA) was applied to obtain thermogravimetric data. Each sample of approximately $5 \mathrm{mg}$ was conducted at $30{ }^{\circ} \mathrm{C}$ to $800{ }^{\circ} \mathrm{C}$ with a constant heating rate of $20^{\circ} \mathrm{C} / \mathrm{min}$ under a flow of $40 \mathrm{~mL} / \mathrm{min}$ of nitrogen atmosphere.

\section{Termite resistance of biofoams}

Coptotermes formosanus (Brechtel State Park, Algiers, LA, USA) were used to test the termite resistance performance of biofoams in according to AWPA E1-17 (American Wood Production Association Standard 2017). The test specimens were put into vessels and exposed to the termites for 4 weeks. Then, the weight loss was calculated to evaluate the termite resistance of biofoams.

\section{Statistical analysis}

Statistical analysis was carried out using SAS (version 9.1, SAS Institute, Cary, NC). The mean and the standard deviation were calculated, and analysis of variance (ANOVA) was performed to determine significant difference $(\alpha=0.05)$ among the samples.

\section{RESULTS AND DISCUSSION}

\section{FTIR Spectra of Biopolyols}

Figure 1 presents the typical IR spectra of Yaupon holly biopolyols. For instance, the presence of hydroxyl groups was observed from peaks of $3450 \mathrm{~cm}^{-1}$ (Huang et al. $2017 b$ ). The characteristic absorbance was calibrated and normalized by referring to the baseline and phenyl band at $1597 \mathrm{~cm}^{-1}$. When the content of Yaupon holly was increased from $10 \%$ to $20 \%$, the intensity of hydroxyl groups increased. It was ascribed to the increased hydroxyl content in biopolyol derived from higher biomass liquefaction. However, by further increasing Yaupon holly content from $20 \%$ to $30 \%$, the intensity of $3450 \mathrm{~cm}^{-1}$ decreased. This was because a higher biomass to solvent ratio resulted in a lower liquefaction yield (Huang et al. 2017b).

The absorbance band at $1730 \mathrm{~cm}^{-1}$ was due to either the vibration of the uronic ester and acetyl groups in hemicellulose, or the ester linkage of carboxylic groups of p-coumaric and ferulic in lignin (Flauzino Neto et al. 2013). It increased with increasing biomass content, which was attributed to a higher content of biomass being dissolved in biopolyol. 


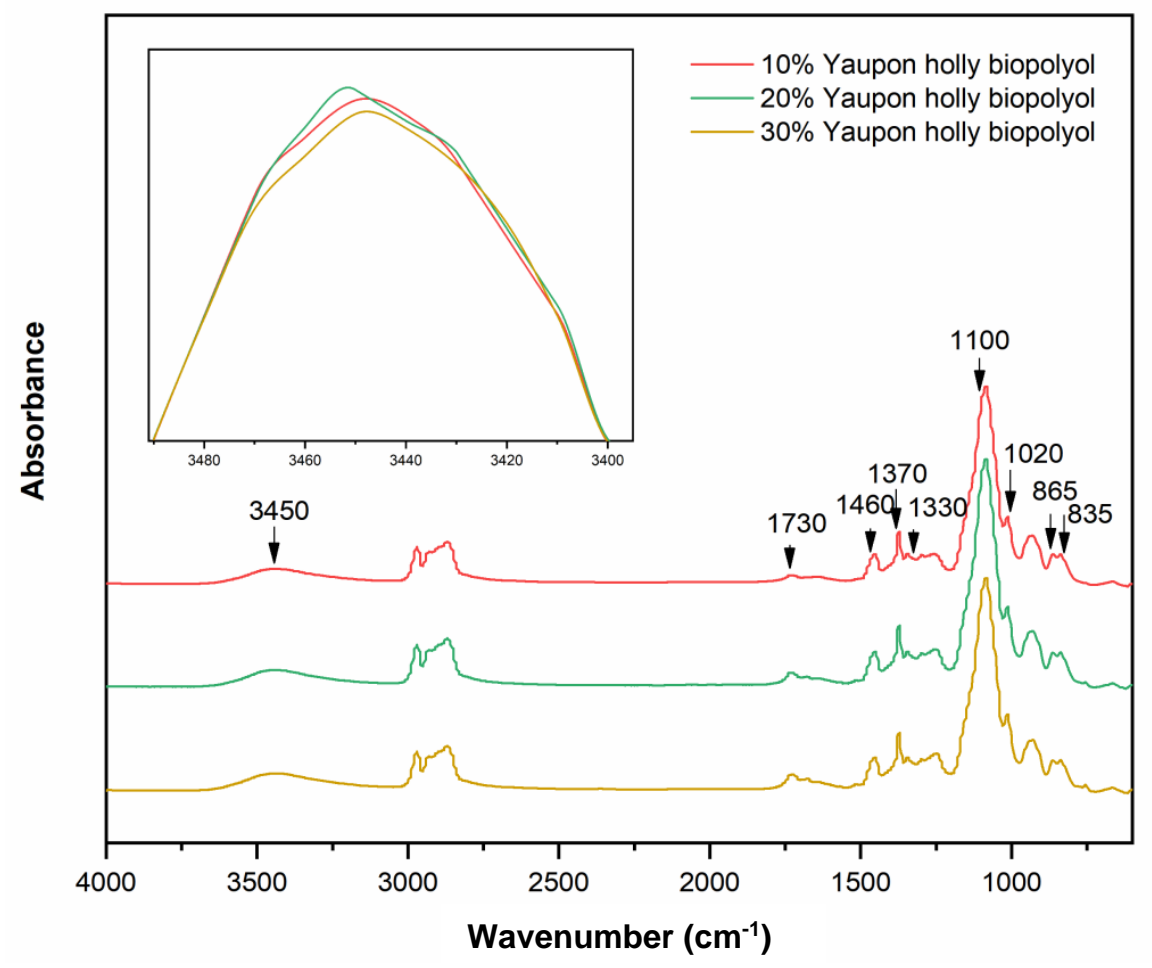

Fig. 1. FTIR spectra of Yaupon holly biopolyol via microwave liquefaction

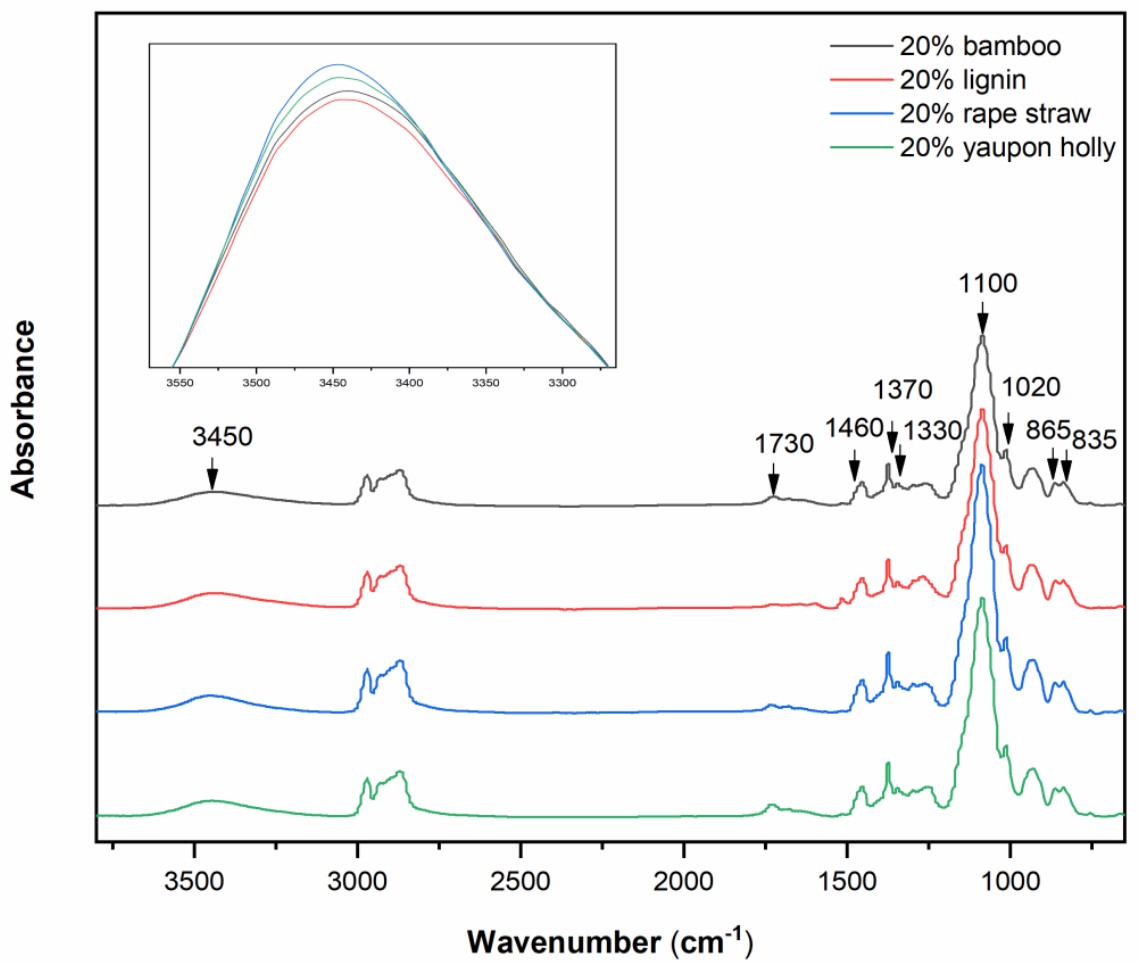

Fig. 2. FTIR spectra of biopolyol derived from different biomass sources via microwave liquefaction 
The peak at $1460 \mathrm{~cm}^{-1}$ arose from $\mathrm{C}-\mathrm{H}$ bending on the benzene ring (Alemdar and Sain 2008). The absorbance bands at $1370 \mathrm{~cm}^{-1}$ corresponded to phenolic $\mathrm{OH}$ groups (Huang et al. 2017b). The peaks at $1330 \mathrm{~cm}^{-1}$ were associated with the syringyl unit (Alemdar and Sain 2008). The prominent peaks at $865 \mathrm{~cm}^{-1}$ and $835 \mathrm{~cm}^{-1}$ were assigned to two adjacent hydrogen atoms on the benzene ring ( $\mathrm{Li}$ et al. 2015). The $\mathrm{C}-\mathrm{O}-\mathrm{C}$ peak at $1020 \mathrm{~cm}^{-1}$ and $1100 \mathrm{~cm}^{-1}$ were assigned to the stretching vibration of $\mathrm{C}-\mathrm{O}$, and attributed to the degradation of cellulose (Alemdar and Sain 2008).

Figure 2 clearly shows the typical bio-based polyol FTIR spectra with hydroxyl groups' absorption peaks at $3450 \mathrm{~cm}^{-1}$, cellulosic groups' absorbent bands at $1020 \mathrm{~cm}^{-1}$, and lignin composition bands at $1370 \mathrm{~cm}^{-1}$, etc. Because polyurethane foam from different biomass sources were compared in this work, the specific hydroxyl groups at $3450 \mathrm{~cm}^{-1}$ were sorted in descending order as follows: rape straw, Yaupon holly, bamboo, and lignin.

\section{Rheological Properties of Biopolyols}

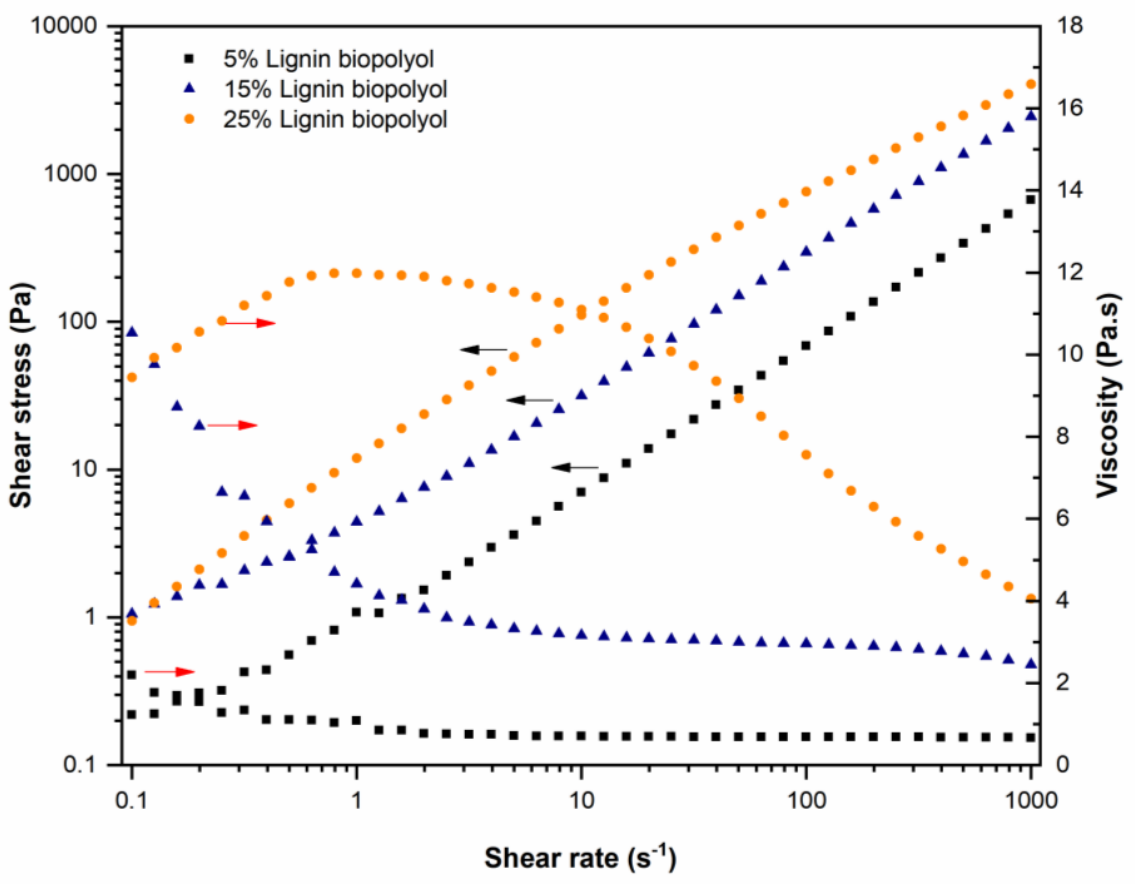

Fig. 3. Rheological properties of biopolyols with varying lignin contents

Lignin-based biopolyols were selected for analysis of the variation of rheological properties with increasing biomass content. Figure 3 shows the shear stress of biopolyols with respect to shear rate. The non-linear increase tendency of shear stress was observed in all the biopolyols with the increase of shear rate. A higher shear stress was observed when the biomass content increased, which was ascribed from the high viscosity, requiring higher shear stress to move. With an increasing shear rate, nonlinear reductions on the viscosity of biopolyols were found in Fig. 3. The decreasing tendency was attributed to the increase of liquid flow arrangement that resulted from increasing shear rate (Khalil and Jan 2012). The disproportionality of viscosity at low shear rates indicated that biopolyols can be categorized as non-Newtonian liquids (Li et al. 2016). The increasing viscosity corresponded to an increase in lignin content, which was attributed to more biomass dissolved with liquefaction. 
The estimated mathematical models are shown in Table 1 . Larger $\mathrm{R}^{2}$ values were observed in the Sisko models, compared with in the Herschel-Bulkley models, confirming that the Sisko model was more appropriate for describing the rheological properties of biopolyol. However, the Herschel-Bulkley model provided the yield stress (intercept, $\tau_{0}$ ) directly, indicating that the minimum shear stress was able to move the fluid. The yield stress remarkably increased when the lignin content increased from $5 \%$ to $25 \%$, suggesting that it was difficult to move the fluid when the biocontent increased. Normally, the fluid could be defined as three types in the base of the flow index values. They types are, respectively, Newtonian $(n=1)$, pseudoplastic (non-Newtonian) with a shear thinning behavior $(n<1)$, and dilatant (non-Newtonian) with shear thickening behavior $(n>1)$ (Khalil and Jan 2012). The flow behavior indexes (n) obtained from the Herschel-Bulkley and Sisko models were lower than 1. This result indicated that the biopolyols were pseudoplastic fluids. It was confirmed that the pseudoplastic biopolyol was suitable for producing bio-based polyurethane foams (Khalil and Jan 2012).

Table 1. Rheological Models of Different Content of Lignin-based Biopolyols

\begin{tabular}{|c|c|c|}
\hline Biopolyols & Herschel-Bulkley Model & Sisko Model \\
\hline \multirow{2}{*}{$5 \%$ lignin } & $y=0.10769+0.74367 x^{0.9846}$, & $y=-1.40488 x+2.14498 x^{0.99509}$, \\
& $R^{2}=0.99999$ & $R^{2}=0.99999$ \\
\hline \multirow{2}{*}{$15 \%$ lignin } & $y=2.93162+5.12324 x^{0.89571}$, & $y=-52.68097 x+57.06588 x^{0.99509}$, \\
& $R^{2}=0.99947$ & $R^{2}=0.99963$ \\
\hline \multirow{2}{*}{$25 \%$ lignin } & $y=4.38339+26.1311 x^{0.73164}$, & $y=-5.19652 x+23.64662 x^{0.86408}$, \\
& $R^{2}=0.99968$ & $R^{2}=0.99994$ \\
\hline
\end{tabular}

\section{FTIR Spectra of Biofoams}

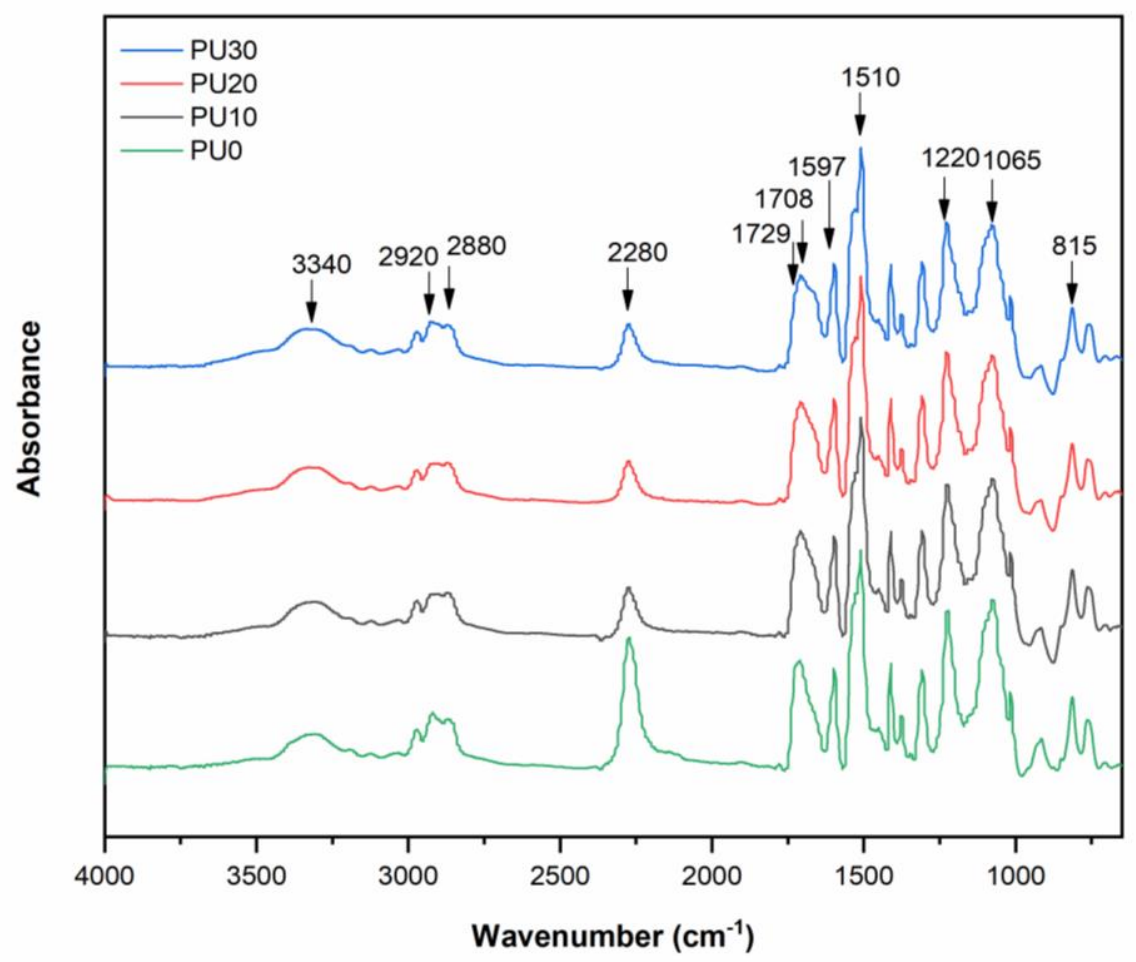

Fig. 4. FTIR spectra of polyurethane foams with varying Yaupon holly contents 
The FTIR spectra of biofoams with different contents of Yaupon holly are shown in Fig. 4. The absorption peaks at $2920 \mathrm{~cm}^{-1}$ and $2880 \mathrm{~cm}^{-1}$ were derived from the $\mathrm{C}-\mathrm{H}$ asymmetric and symmetric stretching vibration of $-\mathrm{CH}_{3}$, respectively, indicating the presence of side chain structural units in lignin (Li et al. 2020). The peaks at $1597 \mathrm{~cm}^{-1}$ and $1510 \mathrm{~cm}^{-1}$ corresponded to the $\mathrm{C}=\mathrm{C}$ stretching vibration of the benzene ring, which are characteristic peaks of lignin (Cheng et al. 2010).

The peak at $2280 \mathrm{~cm}^{-1}$ evidenced the existence of the NCO groups derived from isocynate (Huang et al. 2018a). Its intensity decreased first when increasing the biocontent from 0 to $20 \%$, and then increased as the biocontent increased to $30 \%$. This result was associated with the increase in hydroxyl groups that could react with the NCO group, and then the decrease of liquefaction yield, resulting in the decrease of biopolyol production. The absorbance band at $1729 \mathrm{~cm}^{-1}$ corresponded to the vibration of the uronic ester and the acetyl groups in hemicellulose, or the ester linkage between carboxylic groups of pcoumaric and ferulic in lignin and hemicellulose (Li et al. 2015). The absorbance peak at 1708 in the carbonyl region was ascribed to the $\mathrm{C}=\mathrm{O}$ stretching of ester groups (Ugarte $e t$ al. 2017). The absorption peak at $1220 \mathrm{~cm}^{-1}$ was the $\mathrm{C}-\mathrm{O}$ vibration. The bands located at $815 \mathrm{~cm}^{-1}$ were assigned to the $\mathrm{C}-\mathrm{H}$ bond of the out-of-plane bending vibration absorption peak on the benzene ring of lignin (Ugarte et al. 2017). These peaks were evidence that the liquefaction fragments were involved in the PU foam structure.

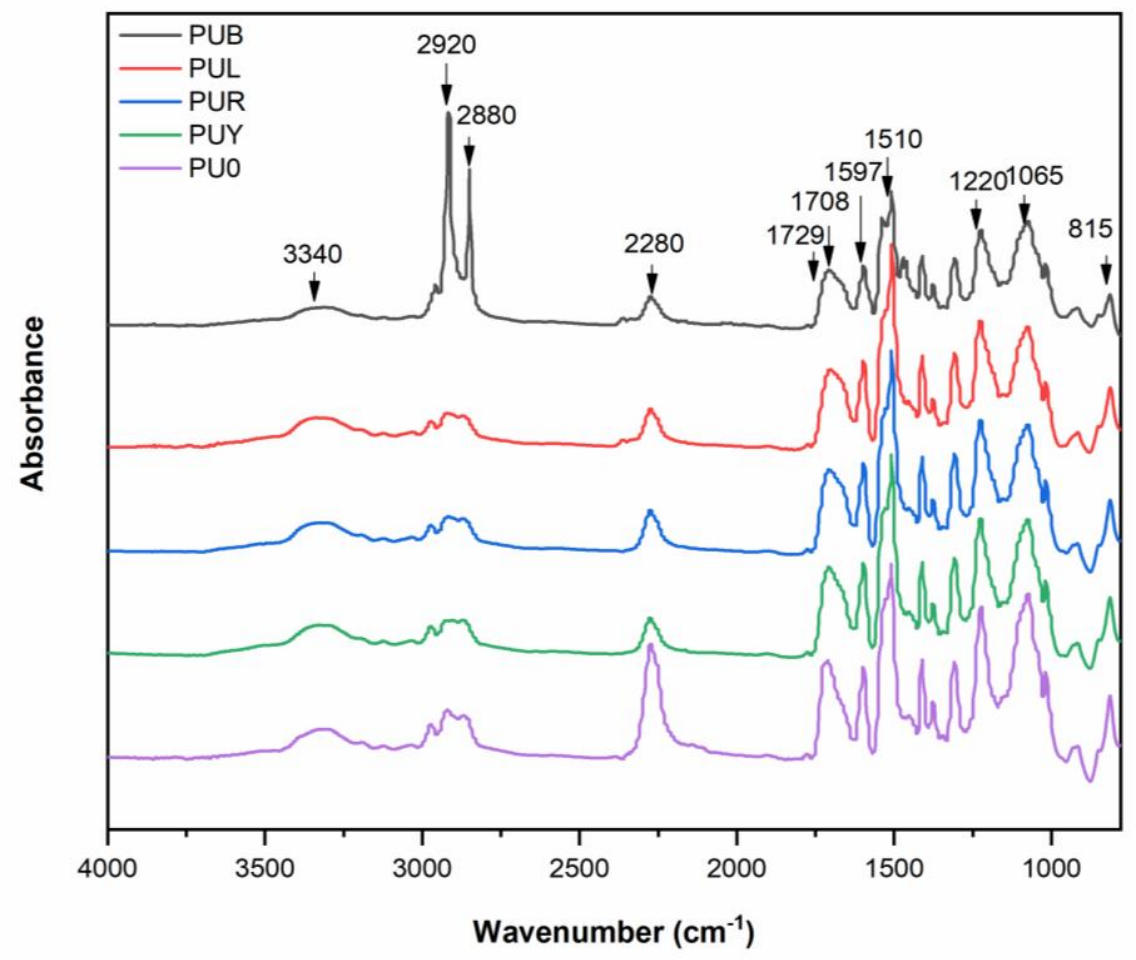

Fig. 5. FTIR of polyurethane foams derived from different biomass sources

The FTIR spectra of biofoams with different biomass sources are shown in Fig. 5. All FTIR spectra had similar shapes and intensities, which indicated that all biomass types had similar ways of participating in the foaming reaction. The intensities of NCO IR peaks of biofoams at $2280 \mathrm{~cm}^{-1}$ were weaker than those of the neat foam. This result further evidenced that the biomass could react with NCO groups. It was noteworthy that the FTIR 
of foams with $20 \%$ bamboo biopolyol had obvious vibrations at the peaks of $2920 \mathrm{~cm}^{-1}$ and $2880 \mathrm{~cm}^{-1}$. The major peak at $2920 \mathrm{~cm}^{-1}$ was derived from the $\mathrm{C}-\mathrm{H}$ asymmetry, and the second one at $2880 \mathrm{~cm}^{-1}$ was caused by symmetric stretching vibration of $-\mathrm{CH}_{3}$. This was because of the presence of the side chain structural units in lignin (Cheng et al. 2010).

\section{Thermogravimetric (TG) and Derivative Thermogravimetric (DTG) Curves of Biofoams}

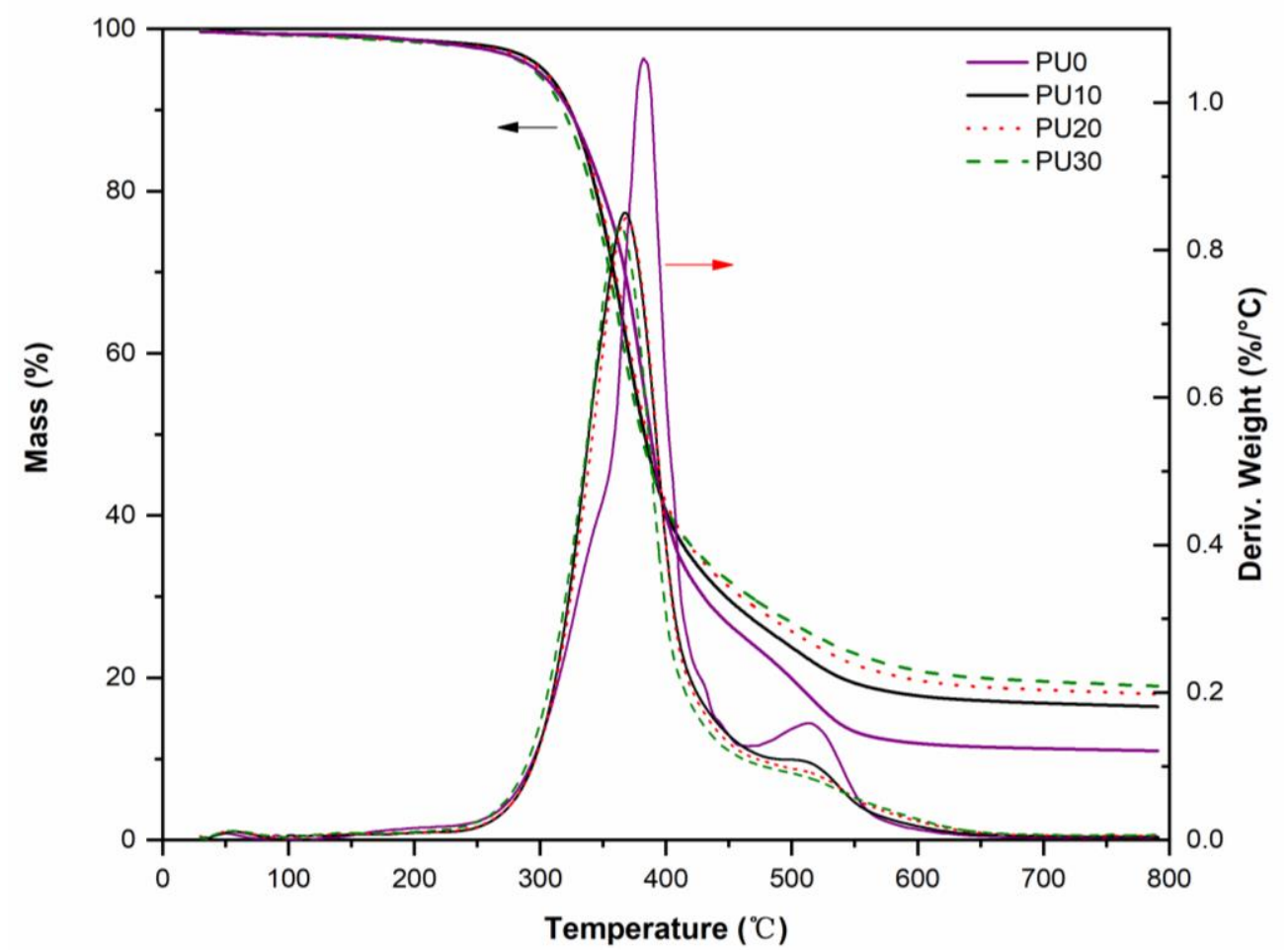

Fig. 6. TG and DTG curves of polyurethane foams with different Yaupon holly contents

The TG and DTG curves of biofoams and neat foams are shown in Fig. 6. There were three distinctive regions of major weight loss for these biofoams. The weight loss up to $100{ }^{\circ} \mathrm{C}$ was considered to be due to the evaporation of moisture and the release of volatile components. The second degradation stage, up to $450{ }^{\circ} \mathrm{C}$, was attributed to the decomposition of hemicellulose fragments, cellulose fragments, unstable urethane links, and rigid segments in polyurethane. The last region, up to $800{ }^{\circ} \mathrm{C}$, was related to the pyrolysis of lignin fragments and the soft segments in foams (Huang et al. 2018a). The biochar residue increased with increasing biomass content. Lower maximum thermal degradation rates were found from biofoams, as compared with neat foam, at about 350$400{ }^{\circ} \mathrm{C}$, which may be related to the higher thermal stability of lignin, crystalline region in cellulose and hemicellulose introduced from biomass sources (Delucis et al. 2018). No remarkable difference in the degradation temperature in the different contents of biomass was observed, except for the soft segments' pyrolysis at approximately $530{ }^{\circ} \mathrm{C}$. The intensity of the pyrolysis of soft segments decreased with increasing biomass content, suggesting the involved biomass changed the polyurethane structure when the content of soft segments decreased. It was worthy of note that the PU0 presented a prominent peak at the region of 450 to $550{ }^{\circ} \mathrm{C}$. This phenomenon was probably due to the decomposition of the organic chain, which was mainly governed by cleavage of urea groups (Gu et al. 2013). 
The thermal degradation properties of biofoams made from different biopolyol sources are shown in Fig. 7. All thermal degradation patterns of biofoams were similar, except for the degradation of soft segments at approximately $530{ }^{\circ} \mathrm{C}$. The thermal stability of soft segments from rape-straw foam was lower than others, which might have been caused by the difference of chemical components among different biomass sources. The thermal stability of urethane links reflects the reaction density between isocyanate groups and hydroxyl groups. From Fig. 7, the degradation temperature of urethane links in biofoams at approximately $375^{\circ} \mathrm{C}$ decreased in the order of rape straw, Yaupon holly, bamboo, and lignin, which was coincidental of the relationship of hydroxyl group IR intensities among different biomass sources. Furthermore, the decomposition temperatures of urethane links from biofoams were lower than that of neat form, which indicated that the introduction of biomass weakened the thermal stability of PU foams.

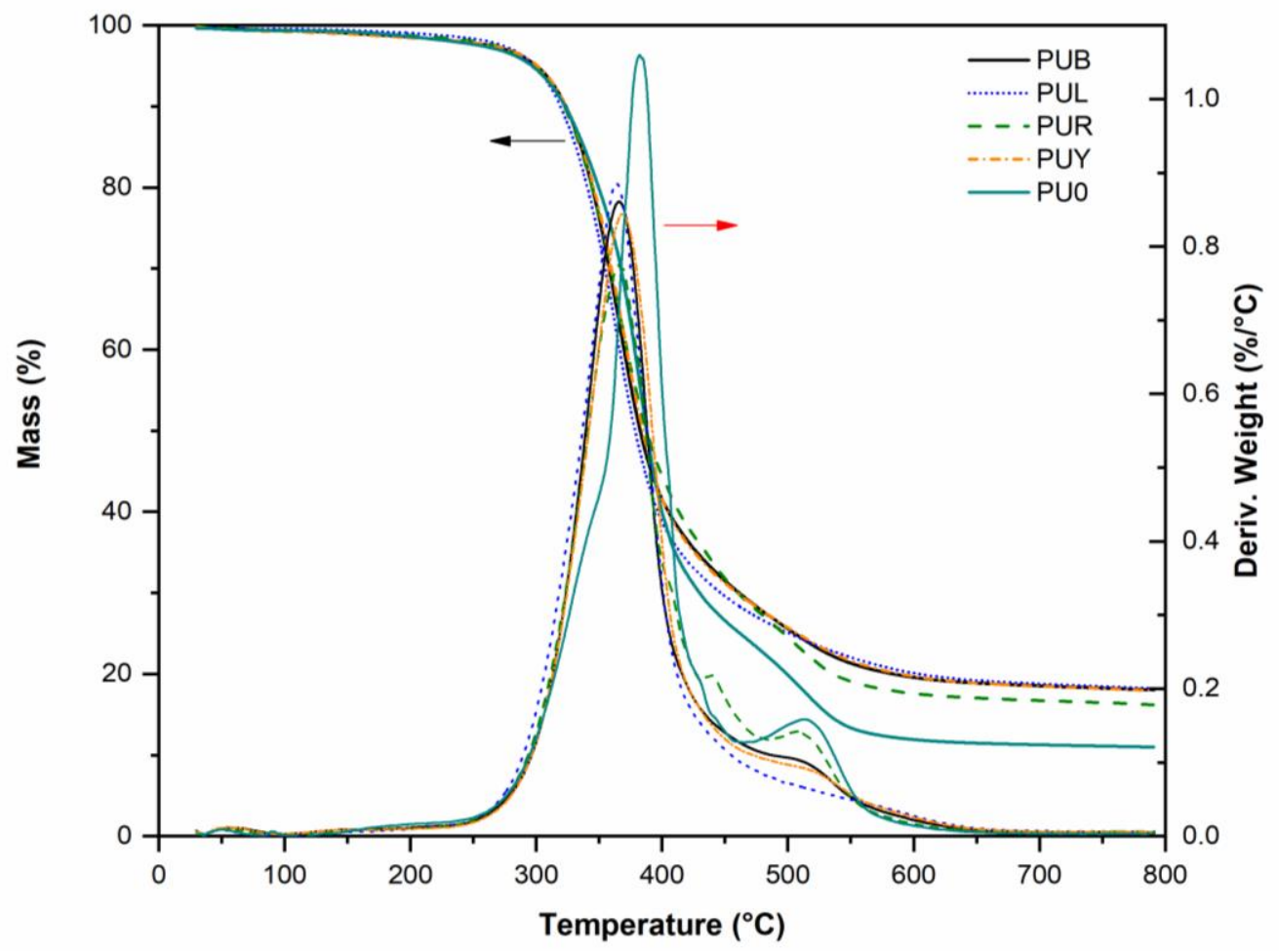

Fig. 7. TG and DTG curves of PU foams with different bio-polyol sources

\section{Compressive Strength of Biofoams}

The compressive strengths of biofoams at $20 \%$ strain with varying biocontents of Yaupon holly are shown in Table 2. The compressive strengths of the biofoams were lower than that of the neat foam. This was ascribed to low crosslinking density between biopolyol and isocyanate (Zhang et al. 2015). As for biofoams, no differences in the compressive strengths between PU10 and PU20 were observed. However, a slight decrease was found when the biomass content increased to $30 \%$. This was attributed to a lower liquefaction yield that accompanied higher biocontent (Huang et al. 2017b). The compressive strength of biofoam with $20 \%$ rape straw was higher than other foams with $20 \%$ biomass. The compressive strength of biofoams was sorted as PUR $>$ PUY $>$ PUB $>$ PUL. This tendency to change was attributed to the change in hydroxyl group content among different biomass sources. 
Table 2. Compressive Strength at $20 \%$ Strain of Biofoams

\begin{tabular}{|c|c|}
\hline PU Foams & Compressive Strength (ठ20\% KPa) \\
\hline PU0 & $148.0 \pm 11.8^{\mathrm{a}}$ \\
\hline PU10 & $53.0 \pm 7.8^{\mathrm{c}}$ \\
\hline PU20/PUY & $53.0 \pm 9.9^{\mathrm{c}}$ \\
\hline PU30 & $40.8 \pm 9.4^{\mathrm{c}}$ \\
\hline PUR & $81.6 \pm 12.6^{\mathrm{b}}$ \\
\hline PUL & $46.9 \pm 4.7^{\mathrm{c}}$ \\
\hline PUB & $51.4 \pm 3.7^{\mathrm{c}}$ \\
\hline
\end{tabular}

Values with the same letters indicate there is no significant difference at 0.05 probability.

\section{Termite Resistance of Biofoams}

Table 3 presents the termite resistance performance of biofoams. The weight loss of the biofoams, except for lignin foam (PUL), was lower than that of PU0, which suggested that the neat foam matrix probably contain a higher content of nutrients needed by termites. The highest weight loss was observed in PUL, which showed that lignin was preferred by the termites (Subekti et al. 2015). When the biomass content increased from $10 \%$ to $30 \%$, the weight loss increased slightly. This was attributed to the higher content of biomass providing a greater amount of food for the termites.

Table 3. Termite Resistance Performance of Biofoams

\begin{tabular}{|c|c|}
\hline Foam Type & Weight Loss (\%) \\
\hline PU0 & $16.8 \pm 4.7^{\mathrm{b}}$ \\
\hline PU10 & $5.7 \pm 1.2^{\mathrm{d}}$ \\
\hline PU20/PUY & $9.0 \pm 4.0^{\mathrm{c}}$ \\
\hline PU30 & $9.5 \pm 1.2^{\mathrm{c}}$ \\
\hline PUL & $22.3 \pm 0.8^{\mathrm{a}}$ \\
\hline PUR & $12.8 \pm 1.4^{\mathrm{c}}$ \\
\hline PUB & $5.6 \pm 0.8^{\mathrm{d}}$ \\
\hline
\end{tabular}

Values with the same letters indicate there is no significant difference at 0.05 probability.

\section{CONCLUSIONS}

1. The FTIR spectra of biopolyols demonstrated the successful liquefaction of biomass, and in biopolyols derived from varying biomass sources, the content of hydroxyl groups was sorted, in descending order, as rape straw, Yaupon holly, bamboo, and lignin.

2. Using rheological analysis, the biopolyols were determined to be pseudoplastic fluids. The yield stress of biopolyols increased remarkably with increasing biomass content.

3. Biofoams had a lower compressive strength than that of neat foam. Nevertheless, the biofoam obtained from biomass sources with higher hydroxyl groups content had better PU performance.

4. Rape straw, Yaupon holly, and bamboo sources in biofoams enhanced the termite resistance performance of PU foams. Lignin had the reverse effect. 


\section{ACKNOWLEDGMENTS}

This work was partially funded by the Manufacture Technology on Light Weight Wood-based Materials (Grant No. 2018YFD0600301). The authors also appreciate the financial support from the Research Start-up Fund on Talents Introduction at Sichuan Agricultural University. The work on Yaupon holly was supported by the USDA Forest Service's Wood Innovation Funding Opportunity Program, Agreement 15-DG-11083150054. Additional support was provided by the National Institute of Food and Agriculture, Mclntire-Stennis project \#LAB94417.

\section{REFERENCES CITED}

Alemdar, A., and Sain, M. (2008). "Biocomposites from wheat straw nanofibers: Morphology, thermal and mechanical properties," Composites Science and Technology 68(2), 557-565. DOI: 10.1016/j.compscitech.2007.05.044

ASTM D695-10 (2010). "Standard test method for compressive properties of rigid plastics," ASTM International, West Conshohocken, PA, USA.

AWPA E1-17 (2017). "Laboratory methods for evaluating the termite resistance of wood-based materials: Choice and no-choice tests," American Wood Protection Association, Birmingham, AL, USA.

Chen, F., and Lu, Z. (2009). "Liquefaction of wheat straw and preparation of rigid polyurethane foam from the liquefaction products," Journal of Applied Polymer Science 111(1), 508-516. DOI: 10.1002/app.29107

Cheng, S., D'cruz, I., Wang, M., Leitch, M., and Xu, C. (2010). "Highly efficient liquefaction of woody biomass in hot-compressed alcohol-water co-solvents," Energy \& Fuels 24(9), 4659-4667. DOI: 10.1021/ef901218w

Da Silva, S. H. F., dos Santos, P. S. B., Thomas da Silva, D., Briones, R., Gatto, D. A., and Labidi, J. (2017). "Kraft lignin-based polyols by microwave: Optimizing reaction conditions," Journal of Wood Chemistry and Technology 37(2), 343-358. DOI: 10.1080/02773813.2017.1303513

Delucis, R. de A., Magalhães, W. L. E., Petzhold, C. L., and Amico, S. C. (2018). "Thermal and combustion features of rigid polyurethane biofoams filled with four forest-based wastes," Polymer Composites 39(S3), E1770-E1777. DOI: $10.1002 / p c .24784$

Flauzino Neto, W. P., Silvério, H. A., Dantas, N. O., and Pasquini, D. (2013). "Extraction and characterization of cellulose nanocrystals from agro-industrial residue-Soy hulls," Industrial Crops and Products 42(1), 480-488. DOI: 10.1016/j.indcrop.2012.06.041

Gama, N. V., Soares, B., Freire, C. S. R., Silva, R., Neto, C. P., Barros-Timmons, A., and Ferreira, A. (2015). "Bio-based polyurethane foams toward applications beyond thermal insulation," Materials \& Design 76, 77-85. DOI: 10.1016/j.matdes.2015.03.032

Gu, R., and Sain, M. M. (2013). "Effects of wood fiber and microclay on the performance of soy based polyurethane foams," Journal of Polymers and the Environment 21(1), 30-38. DOI: 10.1007/s10924-012-0538-y

Hakim, A. A. A., Nassar, M., Emam, A., and Sultan, M. (2011). "Preparation and characterization of rigid polyurethane foam prepared from sugar-cane bagasse 
polyol," Materials Chemistry and Physics 129(1-2), 301-307. DOI:

10.1016/j.matchemphys.2011.04.008

Herschel, V. W. H., and Bulkley, R. (1926). "Konsistenzmessungen von gummibenzollösungen [Measurement of consistency as applied to rubber-benzene solutions]," Colloid Polym. Sci.39, 291-300. DOI: 10.1007/BF01432034

Huang, X. Y., De Hoop, C. F., Peng, X. P., Xie, J. L., Qi, J. Q., Jiang, Y. Z., Xiao, H., and Nie, S. X. (2018a). "Thermal stability analysis of polyurethane foams made from microwave liquefaction bio-polyols with and without solid residue," BioResources 13(2), 3346-3361. DOI: 10.15376/biores.13.2.3346-3361

Huang, X. Y., De Hoop, C. F., Xie, J. L., Wu, Q. L., Boldor, D., and Qi, J. Q. (2018b). "High bio-content polyurethane (PU) foam made from bio-polyol and cellulose nanocrystals (CNCs) via microwave liquefaction," Materials \& Design 138, 11-20. DOI: 10.1016/j.matdes.2017.10.058

Huang, X. Y., Li, F., Xie, J. L., De Hoop, C. F., Hse, C. Y., Qi, J. Q., and Xiao, H. (2017a). "Microwave-assisted liquefaction of rape straw for the production of biooils," BioResources 12(1), 1968-1981. DOI: 10.15376/biores.12.1.1968-1981

Huang, X. Y., Qi, J. Q., De Hoop, C. F., and Xie, J. L. (2017b). “Biobased polyurethane foam insulation from microwave liquefaction of woody underbrush," BioResources 12(4), 8160-8179. DOI: 10.15376/biores.12.4.8160-8179

Kausar, A. (2017). "Polyurethane composite foams in high-performance applications: A review," Polymer-Plastics Technology and Engineering 57(4), 346-369. DOI: org/10.1080/03602559.2017.1329433

Khalil, M., and Jan, B. M. (2012). "Herschel-Bulkley rheological parameters of a novel environmentally friendly lightweight biopolymer drilling fluid from xanthan gum and starch," Journal of Applied Polymer Science 124(1), 595-606. DOI: 10.1002/app.35004

Kosmela, P., Hejna, A., Formela, K., Haponiuk, J. T., and Piszczyk, Ł. (2016). "Biopolyols obtained via crude glycerol-based liquefaction of cellulose: Their structural, rheological and thermal characterization," Cellulose 23(5), 2929-2942. DOI: $10.1007 / \mathrm{s} 10570-016-1034-7$

Li, B., Zhou, M. Y., Huo, W. Z., Cai, D., Qin, P. Y., Cao, H., and Tan, T. W. (2020). "Fractionation and oxypropylation of corn-stover lignin for the production of biobased rigid polyurethane foam," Industrial Crops \& Products 143, Article ID 111887. DOI: 10.1016/j.indcrop.2019.111887

Li, G., Hse, C. Y., and Qin, T. (2015). "Wood liquefaction with phenol by microwave heating and FTIR evaluation," Journal of Forestry Research 26(4), 1043-1048. DOI: 10.1007/s11676-015-0114-0

Li, M. C., Wu, Q., Song, K., De Hoop, C. F., Lee, S., Qing, Y., and Wu, Y. (2016). "Cellulose nanocrystals and polyanionic cellulose as additives in bentonite waterbased drilling fluids: Rheological modeling and filtration mechanisms," Industrial \& Engineering Chemistry Research 55(1), 133-143. DOI: 10.1021/acs.iecr.5b03510

Sisko, A. W. (1958). "The flow of lubricating greases," Industrial \& Engineering Chemistry 50(12), 1789-1792. DOI: 10.1021/ie50588a042

Subekti, N., Yoshimura, T., Rokhman, F., and Masturet, Z. (2015). "Potential for subterranean termite attack against five bamboo species in correlation with chemical components," Procedia Environmental Sciences 28, 783-788. DOI:

10.1016/j.proenv.2015.07.092 
Ugarte, L., Santamaria-Echart, A., Mastel, S., Autore, M., Hillenbrand, R., Corcuera, M. A., and Eceiza, A. (2017). "An alternative approach for the incorporation of cellulose nanocrystals in flexible polyurethane foams based on renewably sourced polyols," Industrial Crops and Products 95, 564-573. DOI: 10.1016/j.indcrop.2016.11.011

Xue, B. L., Wen, J. L., and Sun, R. C. (2015). "Producing lignin-based polyols through microwave-assisted liquefaction for rigid polyurethane foam production," Materials 8(2), 586-599. DOI: 10.3390/ma8020586

Yan, Y., Pang, H., Yang, X., Zhang, R., and Liao, B. (2008). "Preparation and characterization of water-blown polyurethane foams from liquefied cornstalk polyol," Journal of Applied Polymer Science 110(2), 1099-1111. DOI: 10.1002/app.28692

Zhang, C., and Kessler, M. R. (2015). "Bio-based polyurethane foam made from compatible blends of vegetable-oil-based polyol and petroleum-based polyol," ACS Sustainable Chemistry \& Engineering 3(4), 743-749. DOI:

10.1021/acssuschemeng.5b00049

Article submitted: May 13, 2020; Peer review completed: July 12, 2020; Revised version received and accepted: July 19, 2020; Published: July 28, 2020.

DOI: 10.15376/biores.15.3.7034-7047 